\title{
A Case Study of Human Adult Lactose Absorption in Mongolia
}

\author{
KIYOSI TAKAHASI ${ }^{1}$ AND DUBJIR SUvD ${ }^{2}$ \\ 1 Department of Anthropology, Faculty of Science, The University of \\ Tokyo, Hongo, Bunkyo-ku, Tokyo 113, Japan \\ 2 Institute of Biotechnology, Academy of Sciences Mongolia
}

Received December 10, 1992

\begin{abstract}
Human adult lactose absorption in Mongolia is investigated. Each test subject was determined to be a lactose absorber or a malabsorber by the use of a field version of the lactose tolerance test with breath hydrogen determination. The phenotypic frequency of adult lactose absorber in Mongolians was shown to be relatively low compared to other milk using populations in Europe, Arabia and Africa. The frequency was also compared with those of two Chinese populations, Han and Inner Mongolians, where no statistically significant difference was found.
\end{abstract}

Key Words: adult lactose absorption, milk utilization, gene-culture coevolution.

\section{INTRODUCTION}

Some human populations are exceptional among mammals with respect to their relatively high phenotypic frequencies of adult lactose absorbers. Biochemical backgrounds of individuals with different phenotypes, lactose absorbers and malabsorbers, have been examined. Boll et al. (1991) have shown that individuals with different phenotypes can code for identical lactase. This and other studies (e.g., Witte et al., 1990) suggest that differences in posttranscriptional regulation of lactase synthesis may be responsible for the phenotypic polymorphism due to allelic variation at an autosomal regulatory locus (Potter et al., 1985; Sebastio et al., 1989).

Some theoretical models have been proposed to account for the high frequencies of adult lactose absorbers in some populations. For example, Simoons (1970), McCracken (1971) and Kretchmer (1972) proposed adaptive coevolution of a mutant gene and the cultural phenotype of milk utilization in their "culture historical hypothesis." Several field studies have been carried out to estimate the phenotypic frequencies of adult lactose absorbers mainly in populations with dairy cultures, giving theories some numerical data. The frequencies among Kazakh and Inner Mongolians, two Chinese populations with dairy cultures, together with that of Han have been determined by Wang et al. (1984). Since no information about lactose absorption in Mongolia has been obtained, we attempted the study in Mongolia. 


\section{MATERIALS AND METHODS}

The lactose absorption test was held in Ulaanbaatar, the capital of Mongolia, on 20 healthy adults ( 15 females and 5 males) whose ages ranged from 20 to 52 years, with an average age of 32.8 years. Among the subjects 16 are from Khalkha, 2 from Buryat, and 2 from Bait (Bayad).

The test was performed following the procedures of a field version of the lactose tolerance test with breath hydrogen determination (Howell et al., 1981). Test subjects injested lactose monohydrate $(50 \mathrm{~g} / 300 \mathrm{ml}$ water) after at least 8 hours of fasting. Breath samples were collected immediately before, and 120 and 150 minutes after lactose ingestion, by inflating 8 liter balloons with two to three deep expirations. Samples were stored in $350 \mathrm{ml}$ aerosol cans using a hand operating pump. The hydrogen concentrations in these samples were determined by gas chromatography (Howell et al., 1980). The maximal difference in breath hydrogen concentration between one of two samples collected 120 and 150 minutes after lactose ingestion and the sample obtained before lactose ingestion was calculated, being the diagnostic parameter, $\Delta_{\max } \mathrm{H}_{2}$. The subjects who exhibited a substantial increase in $\mathrm{H}_{2}$ concentration $(>20 \mathrm{ppm})$ in their expiratory air after ingestion were identified as lactose malabsorbers, whereas $\Delta_{\max } \mathrm{H}_{2}$ is below $15 \mathrm{ppm}$ in lactose absorbers. Symptoms of lactose intolerance were recorded 150 minutes after the lactose ingestion.

\section{RESULTS}

Fig. 1 shows the distribution of $\Delta_{\max } \mathrm{H}_{2}$ values in the samples of 20 subjects. According to the criteria described in the methods, one subject with $\Delta_{\max } \mathrm{H}_{2}$ value of $-3.0 \mathrm{ppm}$ was determined to be a lactose absorber, while 19 subjects with $\Delta_{\max } \mathrm{H}_{2}$ values between 21.9 and $111.5 \mathrm{ppm}$ were classified as lactose malabsorbers.

Among 19 malabsorbers, 4 reported no symptoms, though 3 of them felt a little nausea. Seven felt flatulence (abdominal gas formation) and eight were reported to have suffered from diarrhoea accompanied by flatulence. The absorber exhibited no symptoms.

In Table 1, the frequency in Mongolians is compared with those of Han and Inner Mongolians. No statistically significant difference was found between the frequency in Mongolians and those of other two. Among the malabsorbers, we could not find any association between $\Delta_{\max } \mathrm{H}_{2}$ values and the severity of the symptoms. 


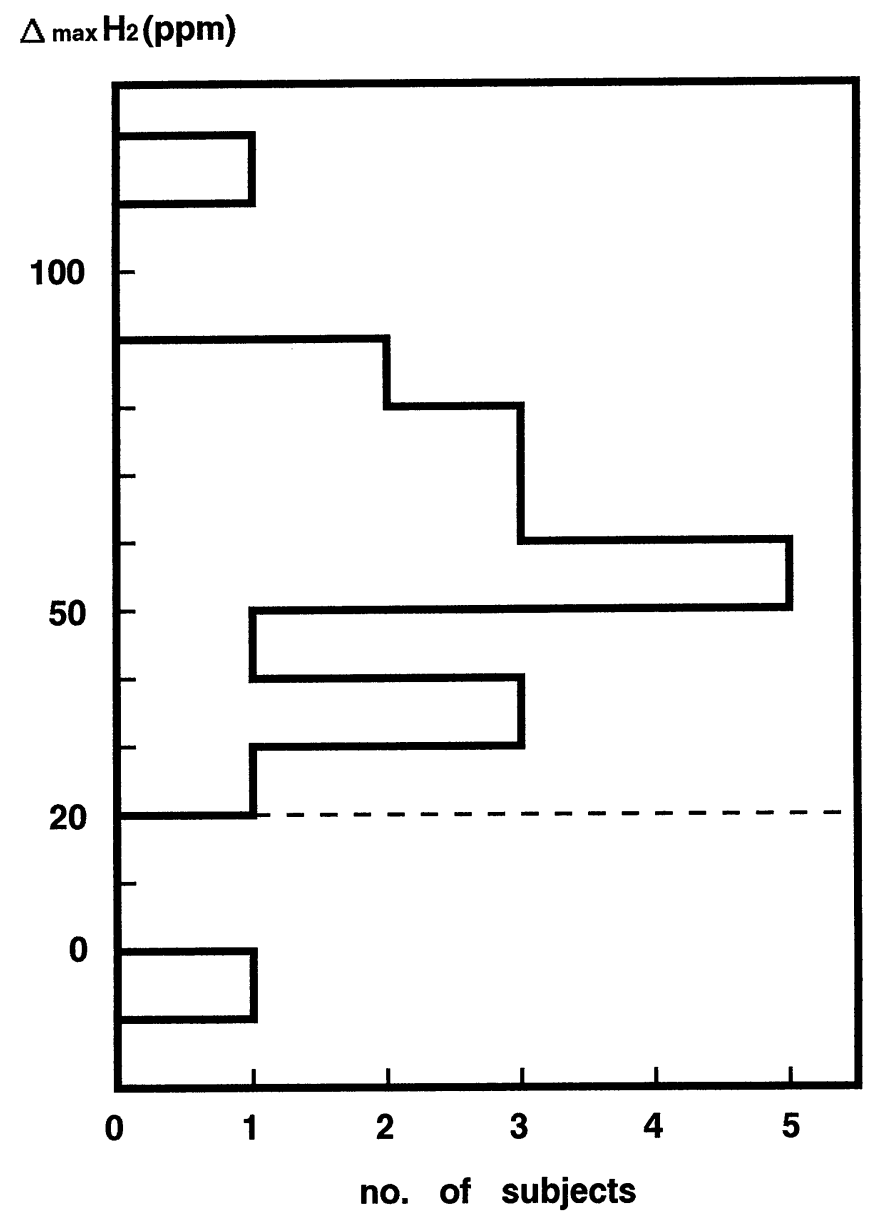

Fig. 1. Distribution of $\Delta_{\max } \mathrm{H}_{2}$ values of 20 subjects.

Table 1. Distribution of lactose absorbers and lactose malabsorbers in two Mongolian populations and Han. In the parentheses are the fractions in percent. Inner Mongolians refers to the Mongolian people now living in the People's Republic of China. Data of Inner Mongolians and Han are cited from Wang et al. (1984).

\begin{tabular}{lcccc}
\hline Population & $\begin{array}{c}\text { Number of } \\
\text { subjects }\end{array}$ & \multicolumn{2}{c}{$\begin{array}{c}\text { Lactose } \\
\text { absorbers }\end{array}$} & $\begin{array}{c}\text { Lactose } \\
\text { malabsorbers }\end{array}$ \\
\hline Han & 248 & 19 & $(7.7 \%)$ & $229(92.3 \%)$ \\
Inner Mongolians & 198 & $24(12.1 \%)$ & $174(87.9 \%)$ \\
Mongolians & 20 & 1 & $(5.0 \%)$ & $19(95.0 \%)$ \\
\hline Total & 466 & 44 & $(9.4 \%)$ & $422(90.6 \%)$ \\
\hline
\end{tabular}

Han: Mongolians $\chi^{2}=0.20,0.6<P<0.7$. Inner Mongolians: Mongolians $\chi^{2}=0.91,0.3<P<0.4$. 


\section{DISCUSSION}

It is believed that Inner Mongolians have mixed with Han, who are traditionally farmers (Batsuur and Dashnyam, personal communication), which might have resulted in genetic divergences of Inner Mongolians from Mongolians. The relatively low phenotypic frequency of adult lactose absorbers in Inner Mongolians, compared to European, Arabian and African populations with frequencies higher than 0.5 (e.g., Kretchmer et al., 1971; Sahi et al., 1973; Bayoumi et al., 1982; Flatz et al., 1982; Hijazi et al., 1983; Flatz et al., 1986), may be due to this admixture with the farming population. According to this view, Mongolians, with less admixture with Han, should show higher phenotypic frequency of adult lactose absorbers, comparable to those of European, Arabian and African populations. This cannot be supported from our present study.

Another explanation may be obtained when we consider the Mongolian way of milk utilization (Nozawa, 1991). Mongolian nomads consume a lot of horse milk as their food resources. The horse milk is known to contain more lactose (6.2 to $6.7 \%$ ) compared to cow milk (4.6\%). Relatively high concentration of lactose causes horse milk to be easily fermented. Fermentation changes lactose into lactic acid and reduces the lactose concentration so that malabsorbers can drink horse milk without experiencing discomfort. Fermented horse milk is one of the main dishes, rather than just a drink, for Mongolian nomads and loved by everyone including juveniles, being the only liquor in Mongolia juveniles are allowed to drink.

With a very low degree of vegetable intake, nomads may sometimes suffer from serious constipation caused by the defficieny of food fiber. Mongolian nomads, in such cases, suffer intentionally from diarrhoea by taking a large quantity of lactose by drinking non-fermented horse milk. It is thought to be very healthy to drink nonfermented horse milk once in a while and is practiced also among many of city residents.

It may be possible that their way of milk utilization, reducing lactose by fermentation, is the cause of the relatively low phenotypic frequency of adult lactose absorbers in Mongolians, for reduction of lactose may also reduce the adaptive differences between lactose absorbers and malabsorbers.

\section{ACKNOWLEDGEMENTS}

This study was accomplished by the support of the following people. First of all, Dr. Kunio Yoshida and Mr. Minoru Yoneda of the University Museum, the University of Tokyo gave us much technical help for the chemical analysis of the study. Professor Hiroshi Wakita and Dr. Yasunori Toshima of the Laboratory for Earthquake Chemistry, the University of Tokyo kindly allowed us to use their apparatus of gas chromatography. We thank Professor Keiichi Omoto of the 
Department of Anthropology, the University of Tokyo and other members for the Population Genetic Studies of Mongolians, who offered a chance to perform this study to one of the authors, Takahasi. We also thank Dr. Kenichi Aoki of the Department of Anthropology, the University of Tokyo for reviewing our study and giving us valuable comments.

Finally, We thank Dr. B. Dashnyam and other researchers at the Institute of Biotechnology, Academy of Sciences Mongolia in Ulaanbaatar for helping us to complete our experiment.

This study was supported in part by Grant-in-Aid for Scientific Research (International Scientific Research Program) from the Japan Ministry of Education, Science and Culture to Professor Keiichi Omoto.

\section{REFERENCES}

Bayoumi, R. A. L., Flatz, S. D., Kühnau, W., and Flatz, G. (1982) Beja and Nilotes: Nomadic pastoralist groups in the Sudan with opposite distributions of the adult lactase phenotypes. Am J. Phys. Anthropol. 58, 173-178.

Boll, W., Wagner, P., and Mantei, N. (1991) Structure of the chromosomal gene and cDNAs coding for lactase-phlorizin hydrolase in humans with adult-type hypolactasia or persistence of lactase. Am. J. Hum. Genet. 48, 889-902.

Flatz, G., Howell, J. N., Doench, J., and Flatz, S. D. (1982) Distribution of physiological adult lactase phenotypes, lactose absorber and malabsorber, in Germany. Hum. Genet. 62, 152-157.

Flatz, G., Schildge, C., and Sekou, H. (1986) Distribution of adult lactase phenotypes in the Tuareg of Niger. Am. J. Hum. Genet. 38, 515-520.

Hijazi, S. S., Abulaban, A., Ammarin, Z., and Flatz, G., (1983) Distribution of adult lactase phenotypes in Bedouins and in urban and agricultural populations of Jordan. Trop. Geogr. Med. 35, 157-161.

Howell, J. N., Schockenhoff, T., and Flatz, G. (1981) Population screening for the human adult lactase phenotypes with a multiple breaths version of the breath hydrogen test. Hum. Genet. 57, 276-278.

Howell, J. N., Von der Fecht, R., and Flatz, G. (1980) Hydrogen breath test for lactose tolerance adapted to population screening. Clin. Chim. Acta 103, 229-231.

Kretchmer, N. (1972) Lactose and lactase. Sci. Am. 277(4), 71-78.

Kretchmer, N., Ransome-Kuti, O., Hurwitz, R., Dungy, C., and Alakija, W. (1971) Intestinal absorption of lactose in Nigerian ethnic groups. Lancet 2, 393-395.

McCracken, R. D. (1971) Lactose deficiency: An example of dietary evolution. Curr. Anthropol. 12, 479-517.

Nozawa, N. (1991) Horses and Nomads in Mongolia, Hara-syobo, Tokyo. (In Japanese)

Potter, J., Ho, M.-W., Bolton, H., Furth, A. J., Swallow, D. M., and Griffiths, B. (1985) Human lactase and the molecular basis of lactase persistence. Biochem. Genet. 23, 423-439.

Sahi, T., Isokoski, M., Jussila, J., Launiala, K., and Pyörälä, K. (1973) Recessive inheritance of adulttype lactose malabsorption. Lancet 2, 823-826.

Sebastio, G., Villa, M., Sartorio, R., Guzzetta, V., Poggi, V., Auricchio, S., Boll, W., Mantei, N., and Semenza, G. (1989) Control of lactase in human adult-type hypolactasia and in weaning rabbits and rats. Am. J. Hum. Genet. 45, 489-497. 
Simoons, F. J. (1970) Primary adult lactose intolerance and the milking habit: A problem in biologic and cultural interrelations. II. A culture historical hypothesis. Am. J. Dig. Dis. 15, 695-710.

Wang, Y.-F., Yan, Y.-S., Xu, J.-J., Du, R.-F., Flatz, S. D., Kühnau, W., and Flatz, G. (1984) Prevalence of primary adult lactose malabsorption in three populations of northern China. Hum. Genet. 67, 103-106.

Witte, J., Lloyd, M., Lorenzsonn, V., Korsmo, H., and Olsen, W. (1990) The biosynthetic basis of adult lactase deficiency. J. Clin. Invest. 86, 1338-1342. 